\title{
Uma análise construcional dos splinters não nativos em uso no português do Brasil
}

\author{
Carlos Alexandre Gonçalves*
}

\begin{abstract}
Resumo
Com base na Morfologia Construcional, modelo desenvolvido por Booij $(2005,2007,2010)$ para o tratamento da morfologia no paradigma da gramática das construções (GOLDBERG, 1995), pretendemos, neste artigo, inventariar partículas do inglês recentemente utilizadas nas estruturas morfológicas do português e descrever as características formais e semânticas das formas complexas ditas híbridas (com uma parte vernácula e outra emprestada). Além disso, procuramos refletir de que maneira novas unidades morfológicas se integram na língua, mostrando que tais unidades se conformam aos esquemas básicos de formação de palavras da língua tomadora. Por fim, pretendemos representar os esquemas e subesquemas de que participam os chamados splinters não nativos, focalizando, para tanto, as formações X-tube, cyber-X e X-pedia.
\end{abstract}

Palavras-chave: Morfologia. Formação de palavras. Construção. Splinter.

\section{Palavras iniciais}

Neste artigo, discutimos o estatuto morfológico de partículas como -tube, cyber- e -pedia, exemplificados em (01) a seguir, observando de que maneira uma abordagem construcional se mostra adequada à análise de elementos alógenos recém-incorporados à língua:

(01) IURD-tube, pornô-tube, UFF-tube, educa-tube ${ }^{1}$

cyber-café, cyber-avó, cyber-cultura, cyber-ataque

bíblia-pédia, dino-pédia, Ryhana-pédia

* Professor Titular da Universidade Federal do Rio de Janeiro (UFRJ). Pesquisador do Conselho Nacional de Desenvolvimento e Pesquisa (CNPq), nível 1, cientista da Fundação de Amparo à Pesquisa no Estado do Rio de Janeiro (FAPERJ).

1 As siglas IURD e UFF equivalem às expressões Igreja Universal do Reino de Deus e Universidade Federal Fluminense, respectivamente. Usamos o hífen apenas para marcar a fronteira de morfemas, sem qualquer compromisso com o novo acordo ortográfico. A forma Ryhana-pédia faz referência à famosa cantora pop de origem barbadiana. 
Com base nos instrumentos da Morfologia Construcional (MC), pretendemos (1) inventariar partículas do inglês recentemente utilizadas nas estruturas morfológicas do português; (2) descrever as características formais e semânticas das formas complexas ditas híbridas (com uma parte vernácula e outra emprestada); (3) refletir de que maneira novas unidades morfológicas se integram na língua; (4) mostrar que tais unidades se conformam aos esquemas básicos de formação de palavras descritos na seção 1; e, por fim, (5) representar os esquemas e subesquemas de que participam os chamados splinters não nativos, denominados xenoconstituintes por Gonçalves; Almeida (2012) e Almeida;Gonçalves (2013). O texto se estrutura da seguinte maneira: em primeiro lugar, definimos splinter para, logo após, apresentar os fundamentos da MC, modelo desenvolvido por Booij $(2005,2007,2010)$ para o tratamento da morfologia à luz da ideia de construção gramatical (GOLDBERG, 1995). A seguir, analisamos, com o instrumental da $\mathrm{MC}$, os esquemas e subesquemas de que participam as formações X-tube, cyber-X e X-pedia. Os dados utilizados na análise foram extraídos de páginas da Internet, com o auxílio da ferramenta eletrônica de busca Google, o que possibilitou o controle de cerca de pelo menos cem instanciações de cada esquema ${ }^{2}$.

\section{Definindo splinters}

Em inglês, splinter originalmente significa "fragmento", "pedaço", "lasca". $\mathrm{Na}$ literatura morfológica, por sua vez, o termo remete a partes de palavras que, retendo o significado da forma original, recorrem numa borda específica de novas formações lexicais (GONÇALVES, 2011b). Por se tratar de um termo técnico, preferimos não traduzi-lo e o fizemos por dois motivos, fundamentalmente: (a) traduções nem sempre são precisas para caracterizar unidades como essas e (b) acreditamos que a literatura da área precisa adotar um vocabulário universal para evitar a proliferação de vários termos técnicos usados em referência a uma mesma entidade. Em relação a esse constituinte, Correia (2003), seguindo Corbin (2000), faz uso do termo "fractoconstituinte". Andrade (2013), por sua vez, reporta-se a essas formas com a expressão "fragmento lexical".

Bauer (2005) assim se posiciona em relação a essas unidades morfológicas: "por splinter entendo um fragmento de palavra usado repetidamente na formação

2 Aproveitamos a oportunidade para agradecer as bolsistas de Iniciação Científica Ana Clara Brum e Carolina Castro da Exaltação pelo rigoroso levantamento dos dados. 
de novas palavras" (BAUER, 2005, p.105, grifo nosso). Ao afirmar que splinters surgem do processo de blending (cruzamento vocabular), Bauer (op. cit., p.105) ressalta que o emprego que faz do termo "é uma pequena extensão do uso encontrado em Adams (1973: 142)". A “pequena extensão" a que o autor se refere é a recorrência de tais partículas. Por isso mesmo, em Bauer (2005), splinter deixa de ser concebido apenas como uma porção aleatória de palavras para ser interpretado como categoria morfológica com estatuto parecido com o dos afixos, já que splinters são agora encarados como entidades que podem levar à criação de novos formativos. Essa ideia aparece bem resumida no seguinte definição de Bauer (2004) em seu "Glossary of Morphology”:

Splinter é uma parte de uma palavra que, devido a algumas reanálises da estrutura da palavra original, é interpretada como significativa e posteriormente utilizada na criação de novas palavras. Como exemplo familiar, considere a palavra 'alcoholic'. Em termos morfológicos, esse vocábulo é dividido em 'alcohol' e -ic. Mas essa palavra foi reanalisada como alc-oholic, e o novo splinter -oholic (variavelmente soletrado), em seguida, reocorre em palavras como chocoholic, spendaholic e shopoholic. (BAUER, 2004, p.77)

Fato interessante que vem ocorrendo em português nos últimos anos, como apontado em Gonçalves; Almeida (2012) e Almeida; Gonçalves (2013), é o uso cada vez mais frequente de splinters do inglês em novas formações lexicais do português que não constituem, necessariamente, empréstimos: essas partículas são utilizadas para criar novas palavras na língua tomadora, o português, já que podem ser adjungidos a formas vernáculas sem qualquer respaldo na língua tomadora, a exemplo de IURD-tube (site de vídeos da Igreja Universal do Reino de Deus), $e$-social (projeto do governo federal unifica o envio de informações pelo empregador em relação aos seus empregados) e prova-cast (áudios de provas, via celular, destinados a concurseiros).

Entre as partículas do inglês encontradas em português, destacam-se, como as mais antigas: (a) -gate, que designa algum tipo de escândalo envolvendo o elemento que aparece na primeira posição; (b) pit-, que remete a alguém caracterizado como agressivo, à semelhança do cão da raça pitbull; e (c) -burguer, relacionado ao sanduíche de carne moída que pode se combinar com mais ingredientes.

O exemplo mais clássico na literatura é o de -gate, analisado com detalhes em Bauer (2005), mas também comentado por vários outros morfólogos (p. ex., KATAMBA, 1990; KEMMER, 1996), inclusive brasileiros (BASÍLIO, 1997; 
FURTADO, 2011). A forma -gate, apesar de equivaler a uma palavra em inglês, é inteiramente desprovida de significado em 'Watergate', forma de onde se desgarrou. 'Watergate' é um complexo de escritórios e apartamentos localizado em Washington. Tornou-se famoso, na década de 1970, após o assalto que levou ao histórico escândalo de corrupção envolvendo o então presidente Richard Nixon. Devido à grande repercussão do caso, que culminou na renúncia do presidente, a forma -gate passou a denominar escândalo e, ao se anexar a nomes próprios, criou inúmeras novas formas em inglês, a exemplo de 'Irangate', 'Bushgate', 'Monicagate' e 'Dakotagate'. Várias palavras em -gate foram criadas em português e até hoje, quatro décadas depois do caso, essa forma ainda é utilizada em nossa língua, principalmente na escrita. A título de exemplificação, vejam-se os dados abaixo, todos extraídos de Gonçalves (2011a: 70):

(02) Banheiro gate: escândalo vergonhoso para os aldeenses. A presidência da Câmara Municipal resolveu quebrar a parede de vários gabinetes para juntálos, diminuindo o número de 15 para 10 unidades, dotar esses gabinetes de um banheiro privativo com chuveiro para os vereadores.

(03) Foram vários, mas o caso mais vergonhoso foi o Piquet-gate. A fórmula 1 infelizmente é marcada por corrupção.

(04) A Justiça os considera envolvidos no "escândalo da maleta“, também ironicamente chamado de Maleta-gate.

A palavra inglesa 'pitbull' designa uma raça canina de origem norteamericana originalmente criada para o combate. Trata-se de um cão atleta, fruto do cruzamento do antigo bulldog (daí a presença de -bull em sua estrutura) com cães da raça terrier, inicialmente usados para perseguir touros e bastante hostis com outros cachorros. Como se pode perceber, o pitbull é um cão extremamente forte e algumas pessoas direcionaram seus talentos para os esportes de luta. De acordo com a Wikipédia " "a tenacidade dessa raça e a força que a acompanha são incomparáveis no mundo canino" e, por isso mesmo, o pitbull é um cão temido por muitos e possui péssima reputação, uma vez que há vários episódios desagradáveis envolvendo a (suposta) agressividade desses animais.

Apesar de -bull, por sua recorrência em inglês, ter mais condições de atuar em formações para além do domínio canino, foi a sequência pit-, em português (e não inglês), que ganhou estatuto morfológico. Obviamente, a palavra-fonte foi pitbulll, que, geralmente por ter proprietários do sexo masculino, a maioria

3 Disponível em https://pt.wikipedia.org/wiki/Pit_bull. 
de grande porte físico e habitualmente envolvida em brigas, acabou espelhando a criação de 'pitboy'. Dentre os elementos comuns ao estereótipo do 'pitboy', estão o de frequentar academias de musculação e praticar artes marciais, bem como acompanhar um pitbull. A imagem a seguir ironiza a agressividade do cão, mostrando que, na verdade, a ferocidade vem do proprietário:

IMAGEM 1: Pitbull e pitboy.

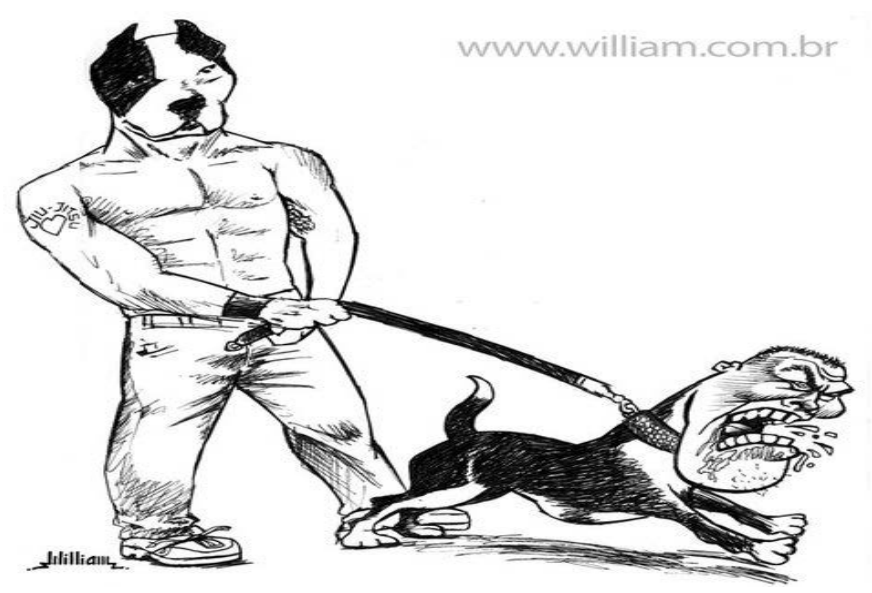

Em função do uso cada vez mais frequente de pitboy, dado o constante envolvimento desses indivíduos em casos policiais, pit- passou a designar, nas construções morfológicas em que fixou à esquerda (em conformidade com os modelos, 'pitbull' e 'pitoby'), "agressivo, violento, feroz", como se vê nos dados em (05), todos extraídos de Gonçalves; Almeida (2012, p.110):

$$
\begin{aligned}
\text { pit-babá } & \text { pit-pai } \\
\text { pit-bicha } & \text { pit-bebê } \\
\text { pit-sogra } & \text { pit-namorado }
\end{aligned}
$$

Um splinter já trazido pronto da língua de origem e usado como palavra é burger, resultado da decomposição sublexical ' 'ham+burger', em que a sequência ' ham' formalmente se assemelha à palavra que nomeia presunto em inglês ('ham'), mas originalmente nada tem a ver com esse embutido, uma vez que constitui

4 Tipo de analogia envolvendo a estruturação interna de palavras, em que, por questões expressivas e com base unicamente na forma (GONÇALVES; ANDRADE. ALMEIDA, 2010), reconhecem-se duas ou mais unidades lexicais em itens não necessariamente complexos, como em 'pressupor' ("por preço em") e "estouro' ("boi que passou por operação de mudança de sexo"). 
empréstimo: hamburger vem de Hamburgo, uma cidade da Alemanha. Com isso, burger passa a denominar o próprio sanduíche e se combina com outras palavras para referenciar novos ingredientes contidos na iguaria: fishburger, chickenburger, cheeseburger.

Quando a palavra cheeseburguer chega ao português, passa por um processo bastante interessante: em decorrência de a pronúncia de 'queijo' (cheese) se assemelhar à da letra $\mathrm{X}$ (xis), essa unidade passa a designar o próprio sanduíche. Dessa maneira, $\mathrm{X}$ referencia o próprio hambúrguer e, se a carne for frango, temse 'X-frango'; se for de picanha, 'X-picanha' e assim por diante: 'X-bacon', 'X-alcatra', 'X-filé', 'X-lombinho' etc.

A letra $\mathrm{X}$, portanto, passa a designar o próprio sanduíche, adquirindo, com isso, estatuto de radical na formação de novos compostos. Nem de longe lembra o opaco cheese do inglês, já que aparece, inclusive, em $X$-queijo. Perini-Santos; Melo (2011, p.22) elencam várias construções X-N, em que o elemento à direita especifica o conteúdo mais saliente do sanduíche. Em (06), observam-se usos mais descritivos, em oposição a (07), exemplos que os autores denominam de "metafóricos, metonímicos ou jocosos" (p. 22) :

(06) X-salada, X-polenta, X-coração, X-ovo, X-batata, X-banana, X-peixe, $\mathrm{X}$-presunto, X-peru, X-peru-bacon, X-calabresa.

(07) X-tudo, X-tudão, X-saturno, X-vênus, X-monstro, X-princesa, $\mathrm{X}$-montanha, X-vegana.

Gonçalves (2016) lista os principais splinters não nativos em uso no português contemporâneo. $\mathrm{O}$ quadro a seguir inventaria esses elementos e fornece, além do significado e da forma plena de origem, algumas criações vernaculares envolvendo cada partícula importada do inglês e hoje tão nossa quanto deles:

QUADRO 1: Principais splinters do inglês em uso no português

\begin{tabular}{|l|l|l|l|}
\hline Elemento & Forma de origem & Significado & \multicolumn{1}{|c|}{ Exemplos } \\
\hline cyber- & Cybernetics & 'digital' & $\begin{array}{l}\text { ciber-ataque, ciber-café, } \\
\text { ciber-crime, ciber-cultura, } \\
\text { ciber-espião , ciber- } \\
\text { guerra }\end{array}$ \\
\hline
\end{tabular}




\begin{tabular}{|c|c|c|c|}
\hline wiki- & Wikipedia & $\begin{array}{l}\text { 'enciclopédia } \\
\text { virtual sobre' }\end{array}$ & $\begin{array}{l}\text { wiki-novela, wiki-aves, } \\
\text { wiki-flora, wiki-juris, wiki- } \\
\text { mapia, wiki-imagem }\end{array}$ \\
\hline$e-$ & Eletronic & $\begin{array}{l}\text { 'pelo } \\
\text { computador' }\end{array}$ & $\begin{array}{l}\text { e-comunidade, e-vendas, } \\
\text { e-negociação, } \\
\text { e-chantagem, e-mediador, } \\
\text { e-professor }\end{array}$ \\
\hline$i-$ & I-pod & $\begin{array}{l}\text { 'pessoal'; } \\
\text { 'meu' }\end{array}$ & $\begin{array}{l}\text { i-Phone, i-Mac, i-Tablet, } \\
\text { i-namoro, i-amigo }\end{array}$ \\
\hline pit- & Pitbull & 'agressivo' & $\begin{array}{l}\text { pit-babá, pit-pai, pit-bicha, } \\
\text { pit-bebê, pit-sogra, pit- } \\
\text { namorado }\end{array}$ \\
\hline -leaks & Wikileaks & $\begin{array}{l}\text { 'vazamento } \\
\text { de } \\
\text { informação' }\end{array}$ & $\begin{array}{l}\text { Amazônia-leaks, Nikiti- } \\
\text { leaks, planalto-leaks, Lula- } \\
\text { leaks, PT-leaks, orkut- } \\
\text { leaks }\end{array}$ \\
\hline -gran & Instagran & $\begin{array}{l}\text { 'foto digital } \\
\text { de' }\end{array}$ & $\begin{array}{l}\text { pobre-gran, favela-gran, } \\
\text { futi-gran }\end{array}$ \\
\hline -gate & Watergate & 'escândalo' & $\begin{array}{l}\text { banheiro-gate, Piquet-gate, } \\
\text { panetone-gate, maleta-gate, } \\
\text { Mônica-gate }\end{array}$ \\
\hline -cast & Podcast & $\begin{array}{l}\text { 'transmissão } \\
\text { pelo celular' }\end{array}$ & $\begin{array}{l}\text { jornal-cast, série-cast, nerd- } \\
\text { cast, celular-cast }\end{array}$ \\
\hline -tube & Youtube & 'pela internet' & $\begin{array}{l}\text { UFF-tube, pornô-tube, } \\
\text { IURD-tube, brasileirão- } \\
\text { tube }\end{array}$ \\
\hline -burguer & Hamburger & 'sanduíche' & $\begin{array}{l}\text { X-búrguer, fran-búrguer, } \\
\text { Bobs-búrguer, fish-búrguer, } \\
\text { egg-búrguer }\end{array}$ \\
\hline
\end{tabular}

Como se observa no quadro 4, a maioria dos splinters do inglês está diretamente relacionada à informática, à Internet e às novas tecnologias digitais. Pela incontestável relevância dessas áreas nos dias de hoje, tais partículas acabam 
se comportando como formativos também na língua tomadora, quer por meio de empréstimos prontos ('cyber-bullying', 'you-tube'), quer por meio de decalques 5 ('cyber-café', 'e-comércio') ou, por fim, de criações propriamente vernáculas ('e-social', 'Nikiti-leaks')'.

As unidades listadas no quadro 4 apresentam diferentes graus de produtividade em português, sendo algumas mais efêmeras e já quase em desuso, como wiki- e pit-, e outras utilizadas em séries de palavras, como cyber-, de emprego cada vez mais frequente. Além disso, a maioria ainda não está completamente nativizada, como demonstram os exemplos em (08), todos com oscilação ortográfica:

$$
\begin{array}{ll}
\text { cybercafé } \sim \text { cibercafé } \sim \text { ciber café } & \text { nikitileaks } \sim \text { nikitiliks } \\
\text { infotube } \sim \text { info-tube } \sim \text { info tube } & \text { wikicionário } \sim \text { uiquicionário }
\end{array}
$$

Neste artigo, descrevemos, com o instrumental da MC, apenas três construções com splinters não nativos: X-tube, cyber-X e X-pedia. Antes de análise, apresentemos, ainda que brevemente, o modelo que sustenta a análise.

A Morfologia Construcional de Booij (2005, 2007, 2010)

A Morfologia Construcional surge no cenário dos estudos linguísticos como alternativa eficaz para análise de processos morfológicos instáveis, que não podem ser encaixados perfeitamente nos padrões canônicos da composição e da derivação ${ }^{7}$. Booij (2010) faz a seguinte apresentação da teoria:

\begin{abstract}
Na Gramática de Construções, a gramática das línguas naturais é vista como um inventário estruturado de construções, isto é, padrões de forma-significado, em vários níveis de abstração. $\mathrm{Na}$ Morfologia Construcional, nos focamos nas construções no nível da palavra, mas não só elas, como também construções frasais com propriedades de palavras. (BOOIJ, 2010, p.03)
\end{abstract}

Palavras complexas são idiomas construcionais no nível da palavra, apresentando uma parte fixa e uma parte variável - no caso das construções $\mathbf{X}$-nejo(a) ('pagonejo', "mistura de pagode com música sertaneja”; "quintaneja',

$5 \mathrm{O}$ decalque é um empréstimo literalmente traduzido para a língua tomadora, ou seja, em vez de adotar a expressão / palavra originária da língua doadora, faz-se uma espécie de versão nativa, como em 'cachorro-quente' (do inglês 'hot-dog'), 'jardim de infância' (do inglês 'Kindergarten') e 'arranhacéu' (do inglês 'skyscraper').

6 Nikiti constitui referência afetiva à cidade de Niterói (antiga capital do estado do Rio de Janeiro). Desse modo, 'Nikiti-leaks' nomeia o escândalo político envolvendo a prefeitura da cidade, nos anos 2010-2012.

7 A Morfologia Construcional não trata somente desses casos; seu aporte inclui estudos sobre compostos e construções sintáticas e a distinção entre flexão e derivação, além da análise morfológica e semântica de formativos, como é o nosso caso. 
quinta-feira com música sertaneja" e 'gataneja', "mulher bonita que vai às festas sertanejas”), a parte fixa é o formativo -nejo(a) e a variável são os nomes que se adjungem à esquerda. Esquemas construcionais, nos termos de Gonçalves; Almeida (2014: 165), "são padrões gerais de pareamento forma-conteúdo que captam características comuns entre várias instanciações específicas e podem ser usados produtivamente". (GONÇALVES, 2014, p.165).

Um esquema construcional pode gerar subesquemas, que também podem se desdobrar em outros subesquemas, uma vez que são estruturas simbólicas que formalizam conceitos armazenados na memória, a partir da abstração de experiências do mundo em que generalizações são realizadas. Por causa dessa propriedade, Booij (2005) acrescenta a especificação semântica genérica aos esquemas.

Gonçalves; Almeida (2014) discorrem sobre o aporte da Gramática das Construções, buscando uma conceituação para o termo construção que seja mais aproximada do nível da palavra. Assim, definem as construções como "interseções de níveis diferentes da língua organizadas hierarquicamente por meio de ligações por herança em uma espécie de rede ou teia" (GONÇALVES; ALMEIDA, 2014, p.178). As relações de herança, postuladas inicialmente por Goldberg (1995), podem ser especificadas abaixo:

a) Herança por polissemia - refere-se à extensão de significado de uma construção para outra. É o caso do sufixo-dor, que forma agentes profissional ('zelador') e não-profissional ('fraudador'), instrumento ('gravador') e objeto ('pregador').

b) Herança por metáfora - refere-se a duas construções relacionadas por projeção interdominial. É o caso de 'camisinha', "peça que protege partes do corpo em diferentes domínios" (GONÇALVES; ALMEIDA, 2014, p.176).

c) Herança por subparte - ocorre quando uma construção é parte constituinte de outra, como em 'homo', ressemantizada a partir de 'homossexual', passando essa informação em 'homofobia' e 'homoafetivo', diferente do significado no nó mais alto - igual, o mesmo.

d) Herança por instanciação - ocorre quando uma construção apresenta grau de detalhamento maior, como em 'batedeira' e 'iogurteira', que possuem esquemas construcionais específicos em relação ao esquema básico - no primeiro, a base é verbal; no segundo, a base é substantiva.

A partir da noção de esquema construcional e relação de herança, Gonçalves; 
Almeida (2014) propõem o seguinte esquema para o formativo -nejo(a). Nesse esquema, base e produto são indexados pelo símbolo subscrito ${ }_{s}$, que representa a classe dos substantivos. Os subscritos ${ }_{i} e_{j}$ indicam que tanto a base, representada pela variável x quanto o produto fazem parte do léxico. Na formalização a seguir, SEM, que em Booij (2010) é inespecificado, é aqui interpretado como o frame evocado pela palavra-fonte, pois somente desse modo podemos entender que, a partir do mesmo esquema, formam-se três instanciações com semânticas distintas, mas relacionadas. Os símbolos maior que e menor que (respectivamente, $<,>$ ) demarcam o esquema e a seta de mão dupla $(\leftrightarrow)$ relaciona forma e significado no interior do esquema

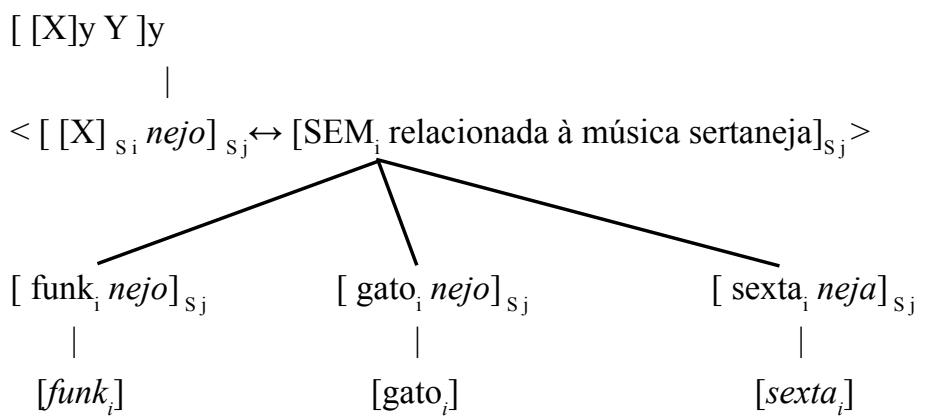

As construções são apresentadas como instanciação do esquema básico de sufixação - [ [X]y Y ]y, em que y é uma etiqueta lexical, X, uma forma livre e $\mathrm{Y}$, uma forma presa à direita. A leitura feita para tal esquema é a de que SEM é interpretado como o frame evocado pela palavra-fonte. Inicialmente, o esquema feito pode aparentar que se trata de uma relação de herança por polissemia, pois é o mesmo tipo de esquema utilizado para o sufixo-dor (GONÇALVES; ALMEIDA, 2014, p.179). Adaptando a representação original de Booij (2005) à morfologia do português, Gonçalves; Almeida (2012) mostram que as três principais operações concatenativas envolvidas na formação de palavras - composição, sufixação e prefixação - podem ser genericamente representadas pelos seguintes esquemas:

(10) (a) composição: $\left.[\mathrm{X}]_{\mathrm{X}}[\mathrm{Y}]_{\mathrm{Y}}\right]_{\mathrm{S}}$

(b) sufixação: $\left[[\mathrm{X}]_{\mathrm{X}} \mathrm{Y}\right]_{\mathrm{Y}}$

(c) prefixação: $\left[\mathrm{X}[\mathrm{Y}]_{\mathrm{Y}}\right]_{\mathrm{Y}}$

Nos esquemas em (10), as variáveis X e Y representam sequências fonológicas e os subscritos ${ }_{X} e_{Y}$, categorias lexicais. O esquema geral dos compostos, em (10a), expressa a generalização de que a composição, independentemente da etiquetagem 
lexical de seus constituintes, sempre forma substantivos em português (daí o rótulo ${ }_{\mathrm{S}}$, após o último colchete). O esquema da prefixação, em (10c), expressa que essa operação é neutra categorialmente, sendo a classe gramatical das palavras prefixadas idêntica à de sua base, que constitui a cabeça. No caso da sufixação, no entanto, o elemento preso porta informação sintática e constitui cabeça categorial (SCALISE et al., 2009), por determinar a classe gramatical do produto. Mais detalhes sobre o modelo serão apresentados a seguir, quando da análise dos três splinters não nativos aqui focalizados: -tube, cyber- e -pedia. Comecemos com -tube.

\section{Algumas notas sobre as formações X-tube}

A expressão inglesa 'You tube' pode ser traduzida como "você no tubo", em que a palavra 'tubo', usada metonimicamente em referência à televisão nessa língua, é hoje empregada para se referir ao monitor (tela do computador), dispositivo pelo qual são veiculadas as imagens fornecidas pela Internet. O 'Youtube' é um site que permite a seus usuários o carregamento e o compartilhamento de vídeos em formato digital, "abrigando uma grande variedade de filmes, clipes e materiais caseiros, geralmente pequenas gravações envolvendo eventos variados: desde os de grande relevância aos mais banais" (ALMEIDA; GONÇALVES, 2013, p.402).. Na página Significados, encontra-se a seguinte definição para 'Youtube':

O termo vem do Inglês "you" que significa "você" e "tube" que significa "tubo" ou "canal", mas é usado na gíria para designar "televisão". Portanto, o significado do termo "youtube" poderia ser "você transmite" ou "canal feito por você". A ideia é idêntica à da televisão, em que existem vários canais disponíveis. (www. significados.com.br/youtube/)

A expressão 'youtube' pode ser considerada o gatilho para a formação de um esquema de formação de palavras, ainda em inglês, pois -tube deixa de significar "tubo, televisão" e passa a designar um site de vídeos, em que o conteúdo das filmagens é evocado pela palavra-base à esquerda. À imagem e semelhança de 'youtube', foram criadas páginas como as seguintes: 'Science Tube', 'Adult Tube', 'CartoonTube' e 'Sextube'). O esquema pode ser representado da seguinte maneira: 
(11)

Youtube $\leftrightarrow$ "você transmite (pela Internet)"

link por subparte

tube $\leftrightarrow$ site de vídeo

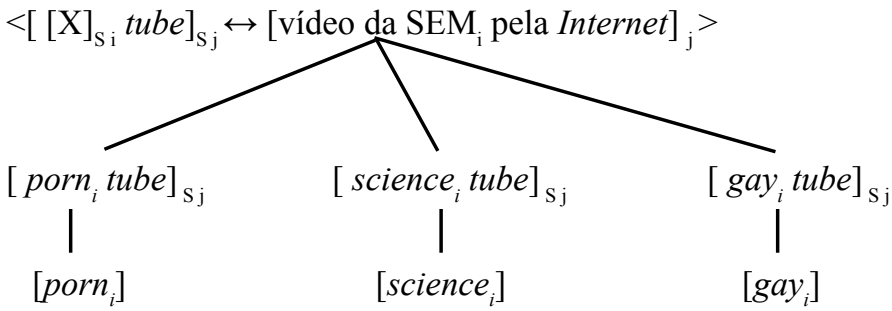

Muitas páginas originalmente em inglês foram decalcadas para nomear as páginas em português de conteúdo equivalente, como é o caso de 'porn tube' e 'sex tube', logo "traduzidas" para 'pornô-tube' e 'sexo-tube'. Temos, nesses dados, nos termos de Assumpção Jr. (1986), "aquisição de forma léxica ou locução estrangeira, através da substituição, por forma léxica vernácula, de significação equivalente criada para esse fim" (ASSUMPÇÃO JR., 1986, p.109). Outras formações, no entanto, não têm qualquer respaldo em inglês, o que nos autoriza afirmar que (a) são construções efetivamente híbridas e (b) o esquema em (11) é válido também para o português. Os exemplos a seguir comprovam essas ideias, uma vez que o elemento à esquerda pode ser, além, de substantivo vernáculo, também uma sigla nativa ou mesmo um splinter do português: 'educatube' (página criada em abril de 2009 para indicar vídeos de e para educadores, além de sugerir diversos recursos tecnológicos com fins educacionais), 'MPBtube' (canal de vídeos da rádio MPB FM, Rio de Janeiro, no qual internautas podem publicar e assistir vídeos relativos à música popular brasileira) e 'pagotube' (blogue com vários clipes de cantores de samba e pagode).

Nos dias de hoje, são várias as palavras construídas em conformidade com o modelo em (88), que se ajusta ao esquema da sufixação em português, [[X]x Y] $\mathrm{y}$, com -tube à direita (o Y maiúsculo da construção), respondendo pela classe do produto (o y minúsculo), sempre um substantivo. Nas formações vernaculares, a parte fixa da construção continua sendo -tube, a despeito de termos a forma 'tubo', que, ao contrário do inglês, não se especializou para designar a própria televisão: fazia referência concreta ao dispositivo usado nas antigas TVs com "tubo de 
imagem". Apesar de termos X-tube, a pronúncia das formas que aparecem nas imagens a seguir - que confirmam a produtividade do esquema em português - é ['tu.bI] (e não ['tfu:b], como em inglês):

IMAGENS 2: Formações com -tube

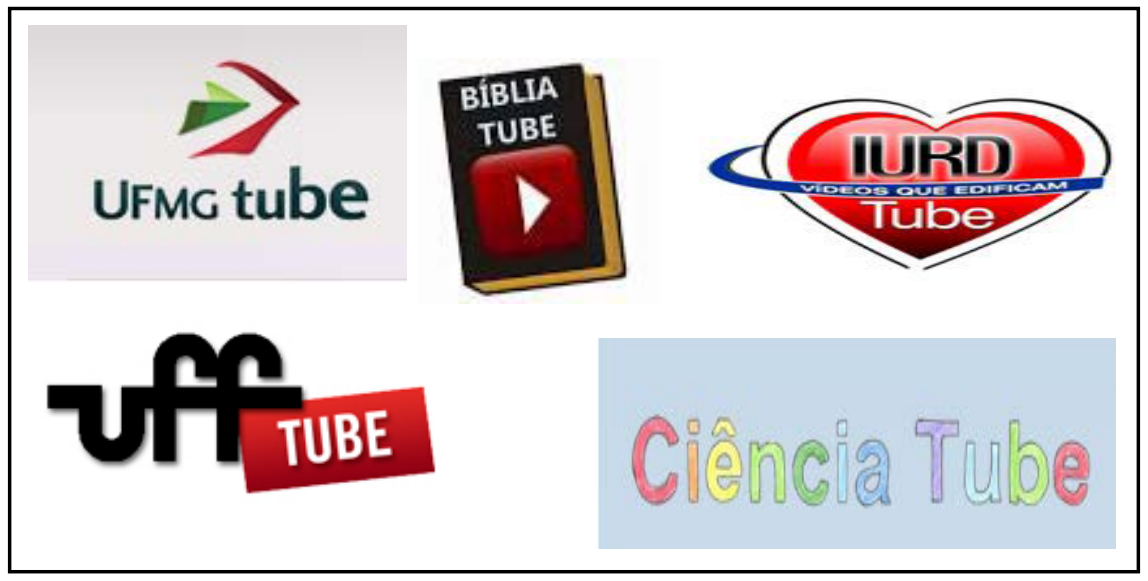

De acordo com com Gonçalves; Almeida (2012), a abundância de palavras com splinters do inglês formadas em português "decorre, sem dúvida alguma, de um movimento cultural relativamente recente, de caráter mundial, em grande parte motivada pela popularização da internet, e pelos desenvolvimentos científicos e tecnológicos que se tornaram mais conhecidos nas duas últimas décadas". (GONÇALVES; ALMEIDA, 2012, p.113-114). Por isso mesmo, cyber- reflete, melhor que qualquer outro splinter, a diversidade de significados em jogo nas formas de comunicação proporcionadas pelas novas tecnologias.

\section{O esquema e os subesquemas das formações cyber-X}

Cyber- constitui encurtamento não morfêmico da palavra 'cybernetics', cuja estrutura interna é cybern-etics, cultismo técnico do grego 'kubernetiké', primeiramente adaptado pelo inglês. 'Cybernetics' contém a sequência -etics - equivalente ao sufixo que, em grego, formava adjetivos e originalmente 
significava "pertencente a, da natureza de" - e a base cubern-, "dirigir". Em grego clássico, kubernetiké passou a designar "timoneiro", ou seja, "condutor que leva o barco ao porto". Para Gonçalves; Almeida (2012), tal forma foi importada pelo latim e passou a nomear o governo dos sistemas físicos automáticos. Com o desenvolvimento da tecnologia, observam os autores, o uso da palavra "estendeuse às máquinas que efetuam movimentos (...). Por fim, em função da revolução eletrônica, a palavra passou a rotular também as condições elétricas, magnéticas e óticas, bases dos processadores digitais e da cibernética atuais" (GONÇALVES; ALMEIDA, 2012, p. 115). De acordo com a Wikipedia,

A cibernética é o estudo interdisciplinar da estrutura dos sistemas reguladores. A cibernética está estreitamente vinculada à teoria de controle e à teoria geral de sistemas. Tanto nas suas origens como na sua evolução, na segunda metade do século XX, a cibernética é igualmente aplicável aos sistemas físicos e sociais. Os sistemas complexos afetam o seu ambiente externo e logo se adaptam a este. Em termos técnicos, centram-se em funções de controlo e comunicação: ambos fenômenos externos e internos do/ao sistema. Esta capacidade é natural nos organismos vivos e tem sido imitado em máquinas e organizações. Presta-se especial atenção à retroalimentação e aos seus conceitos derivados. (WIKIPEDIA, $2016)^{8}$

Com a explosão da era eletrônica, o temo passou a ser utilizado também em referência à Internet ou à comunicação entre usuários das redes sociais, como o antigo Orkut, o Linkedin e o popular Facebook. Em inglês, o splinter 'cyber' também constitui truncamento, já que pode funcionar como forma livre, equivalendo a um adjetivo (12) ou a um verbo (13), compactando, nesse último caso, o significado de 'cybersex' ("fazer sexo pela Internet"):

(12) Is it cybersecurity or cyber security? (dúvida de um internauta se a palavra se escreve junto ou separado, pois, pela posição, cyber pode ser prefixo ou adjetivo). ${ }^{9}$

(13) Cyber crimes are now investigated by INTERPOL ("crimes cibernéticos são agora investigados pela INTERPOL". ${ }^{10}$

8 Disponível em https://pt.wikipedia.org/wiki/Cibern\%C3\%A9tica. Acesso em 20 maio2016.

9 Disponível em http://deepakrout.blogspot.com.br/2015/03/developing-common-understanding-of. html. Acesso em 20 maio 2016.

10 Disponível em http://www.interpol.int/Crime-areas/Cybercrime/Cybercrime. Acesso em 20 maio 2016. 
(14) Do you wanna cyber with me? ("quer fazer sexo virtual comigo?)"11

Pela variabilidade de significados da palavra 'cybernetics', era de se esperar, também, a ampla flexibilidade semântica do splinter cyber-. Na representação a seguir, feita com os instrumentos da MC, exibe-se o comportamento dessa partícula e as instanciações derivadas de cada agrupamento semântico:

(15) cybernetics $\leftrightarrow$ "ciência relacionada à inovações tecnológicas e digitais" |link por subparte

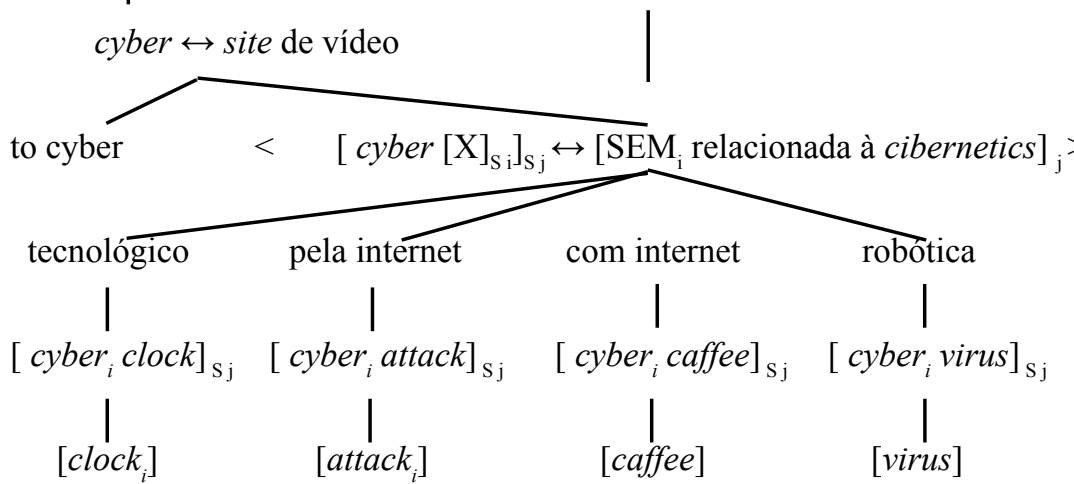

Em português, apesar de existir a palavra 'cibernética' com significados equivalentes aos do inglês, o splinter é não pronunciado ['si.bex], mas ['saj.bex], preservando a pronúncia da língua doadora e, na grande maioria das ocorrências, também a grafia com $<\mathrm{y}>$. Mesmo quando escrito 'ciber-', como em 'ciber-café' e 'ciber-cultura', temos ouvido '['sai.bex]café' e '['saj.bex]cultura', o que mostra a falta de nativização da partícula importada. Assim como em X-tube, várias formas com cyber- são encontradas em português em sua forma original, muitas em decorrência de o elemento em segunda posição também ser um empréstimo não nativizado, como em (15). A maioria, no entanto, constitui decalque, estratégia, para Pisani $(1967,79)$, "especialmente usada quando se devem criar palavras para exprimir um conceito novo chegado do exterior, e não se quer adotar a palavra estrangeira" (PISANI, 1967, p.79), a exemplo das listadas em (16):

(16) cyber-bullying ("assédio pela Internet")

cyber-punk ("punk com roupas tecnológicas")

cyber-affair ("site de relacionamentos amorosos")

cyber-funk ("música funk com toques eletrônicos")

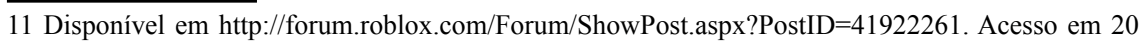
maio de 2016. 
(17) cyber-cozinha ("site dedicado à troca de informações sobre receitas culinárias")

cyber-espaço ("espaço virtual; termo criado pelo ficcionista William Gibson")

cyber-café ("cafeteria que oferece aos usuários acesso à Internet")

cyber-cidades ("espaços/grupos de interação entre usuários da rede")

Em relação ao emprego de cyber- em português, dois aspectos logo se destacam: (a) a ampla oscilação ortográfica e (b) as nuances de significado com bases nativas, nas construções efetivamente híbridas, sem respaldo em inglês. Quanto ao primeiro aspecto, talvez por conta do forte sentimento do empréstimo, em decorrência da pronúncia, há registro de formas escritas aglutinadas ou soltas ('cyberloja' 'cyber loja'), com ou sem hífen (cyberataque $\sim$ cyber-ataque), com $<\mathrm{i}>$ ou $<\mathrm{y}>$ ('cyber-café' 'ciber-café'), com aspas ou outro recurso gráfico que sinalize uma espécie de "autorização" para o uso da forma ("cyber" filho, 'cyber jogador'). Essa variabilidade gráfica sinaliza o baixo grau de nativização da partícula, a despeito de o português apresentar a palavra 'cibernética', escrita aglutinada e com o $<\mathrm{i}>$ representando a vogal [i]. No português europeu, é mais comum a escrita aglutinada e sem hífen do constituinte, embora ainda não tenhamos evidência de sua pronúncia. Por conta da realização com o ditongo [aj], no português brasileiro, vamos representar o splinter sempre com $<\mathrm{y}\rangle$, ainda que eventualmente ocorra a grafia com $<\mathrm{i}>$.

Em relação ao segundo aspecto, tomemos a relação em (18) para refletir sobre o uso e o significado de cada formação propriamente vernácula:

(18) cyber-condria ("doença provocada pelo uso excessivo do computador") cyber-avó ("avó alinhada ao uso de equipamentos eletrônicos")

cyber-inseto ("robô inseto")

cyber-babá ("equipamento de monitoramento de bebês")

cyber-bar ("bar com rede wi- $f$ grátis")

No primeiro caso, cyber- refere-se à causa da patologia no indivíduo (o uso excessivo do computador, quase um vício ou uma droga); no segundo, ao amplo acesso às tecnologias de ponta, como smartphones, i-pods, tablets ou, mesmo, à rede mundial de computadores; no terceiro, a um robô; no quarto, a uma avó moderna, "antenada" com as novas tecnologias Por fim, o último exemplo evoca o uso da Internet no local especificado pela base. As imagens a seguir ilustram esses novos usos de cyber-: 
IMAGENS 3: Formações nativas cyber-X

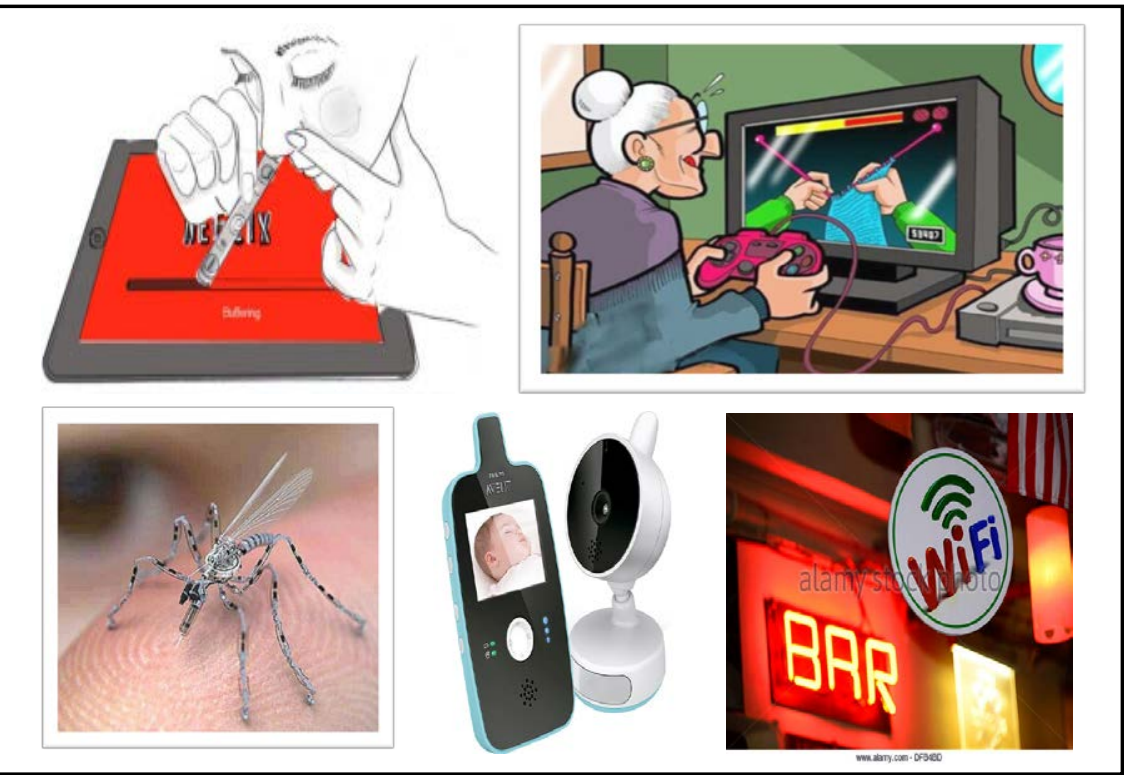

Se as imagens em 7 surpreendem pelas possibilidades de referenciação através de cyber- é porque, nos termos de Soares da Silva (2006), devemos "procurar o significado esquemático de um item, mesmo que ele não exista" (SOARES DA SILA, 2006, p.69): as formações cyber-X, embora sejam semanticamente diversas, podem ser genericamente referenciadas, na esteira de Booij (2010), como relacionadas à tecnologia de ponta, seja essa tecnologia relacionada à área da robótica, da computação ou da informação digital. Do ponto de vista formal, as construções cyber-X associam-se ao padrão de prefixação em português, já cyber-, ao contrário do inglês, é uma forma presa de categoria neutra, pois o elemento à direita constitui cabeça lexical por responder pela classe e pelo gênero do produto, além de ser, também o núcleo semântico. $\mathrm{O}$ esquema a seguir generaliza esses fatos:

(19) cyber-

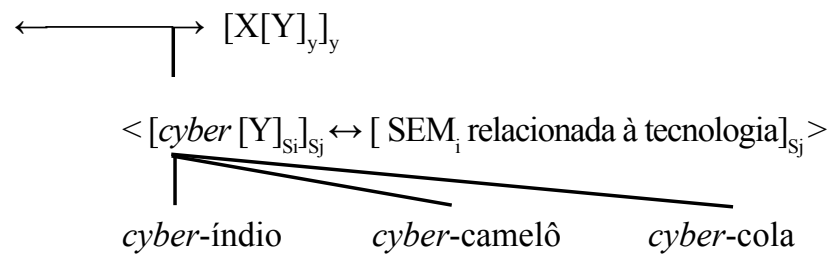


Assim, cyber-, oriundo do encurtamento da palavra inglesa 'cybernetics', passa para o português preservando a pronúncia originária e herda o conteúdo de 'cibernética', ciência que, em linhas gerais, regula o controle automático e a interação homem-máquina. Ajusta-se ao esquema básico da prefixação, [X[Y] $\left.{ }_{\mathrm{y}}\right]_{\mathrm{y}}$, instanciando o padrão [cyber $\left.[\mathrm{Y}]_{\mathrm{Si}}\right]_{\mathrm{Sj}}$ ' 'Cyber-índio' ("índio que domina as tecnologias digitais"), "cyber-camelô' ("camelô que vende produtos eletrônicos" ou "camelô que permite o pagamento com cartão de crédito") e 'cyber-cola' ("consulta indevida feita pela Internet, em provas ou trabalhos), entre outras, são instanciações individuais desse esquema e, por isso mesmo, herdam propriedades desse nó.

\section{As formações X-pedia em português}

Mesmo já fazendo parte das duas línguas, inglês e português, desde o século $\mathrm{XVI}$, por conta do empréstimo direto do grego 'enciclopédia' ('encyclopedia'), o radical neoclássico -pedia (ing.) / -pédia (port.) ${ }^{12}$ só passou a formar novas palavras a partir de 2001, com o surgimento da Wikipedia/Wikipédia, conhecida como a "enciclopédia livre", site colaborativo que reúne mais de 700.000 verbetes criados e atualizados pelos usuários. A forma 'wikpedia' contitui produto do cruzamento vocabular de wiki- (partícula originária do havaiano que significa, na linguagem da informática, "extremamente rápido e colaborativo") com 'encyclopedia'. Com isso, -pedia (['pi:..rie]) assume, em inglês, o significado de "enciclopédia" e passa a nomear qualquer página que aborde, além da palavra, o próprio conceito, o tema ou a disciplina, tratando-os com profundidade, a fim de transmitir o conhecimento acumulado sobre o assunto evocado pela forma à esquerda com que se combina:

(20) soap-pedia - "enciclopédia eletrônica sobre sabonetes"

chemistry-pedia - "enciclopédia sobre química"

Rihanna-pedia - "canal de informações sobre a cantora Rihanna"

12 A palavra 'enciclopédia' provém do grego clássico 'enkyklios paideia', "educação circular”, isto é, “conhecimento geral”. A forma 'paideia' foi trazida para as línguas modernas, preservando o significado de "educação", na forma de ped-, elemento que pode ocorrer na primeira ('pedagogia') ou na segunda posição ('enciclopédia'). 
Em português, a nativização do splinter é total, a ponto de o falante sequer perceber estar diante de um elemento originalmente trazido do inglês, por força da Wikipedia. A relevância das informações veiculadas por essa ferramenta foi tão grande que logo seus conteúdos foram traduzidos para várias línguas, inclusive o português. Desse modo, criamos a Wikipédia, com acento na vogal média aberta $[\mathcal{E}]$, numa clara alusão a 'enciclopédia', palavra que circula em nossa língua há muito tempo.

IMAGEM 4: Logo da Wikipédia (Brasil)

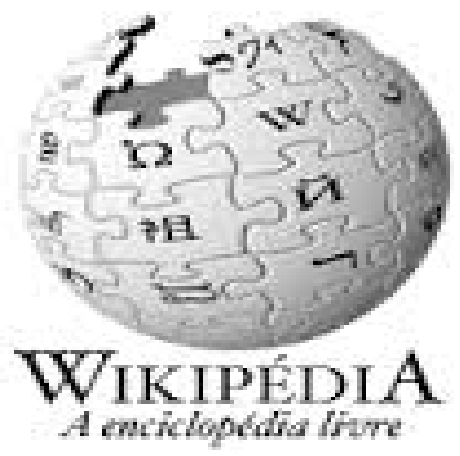

Como splinter, -pédia apresenta muito mais possibilidades de combinação que qualquer elemento neoclássico. Como se vê nos dados abaixo, aparecem, na primeira posição, (a) palavras, (b) siglas, (c) splinters, (d) prefixos, (e) truncamentos, (f) elementos neoclássicos e (g) antropônimos:

(21) a. bíblia pédia, Malucopédia, dinque-pédia

b. CSA pédia, MPBpédia

c. infopédia

d. micropédia, macropédia

e. Flapédia, Flupédia, dinopédia

f. zoopédia

g. Potterpédia

Os dados em (21) mostram que as formas X-pédia não oferecem dificuldades de interpretação, dada a especialização do constituinte, que sempre evoca o domíniomatriz da informação: -pédia pode ser parafraseado como "coletânea digital de informações sobre". Por se fixar na borda direita das novas construções, enquadrase no esquema de sufixação em português, apesar de não funcionar como sufixo 
prototípico, por combinar-se com uma grande variedade de tipos morfológicos (e não com radicais, como os sufixos mais canônicos). O esquema em (22), a seguir, formaliza o comportamento de -pédia. Observe que não deixamos sem etiqueta lexical a informação do input, uma vez que todos os tipos morfológicos envolvidos em (96) podem ser considerados nominais:

(22) wikipédia

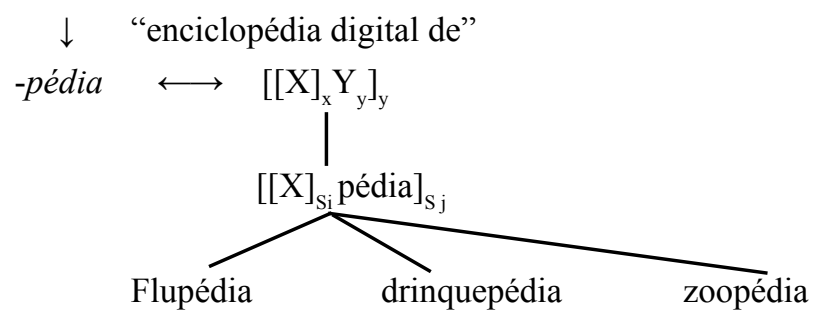

\section{Palavras Finais}

Pelo que se expôs ao longo do capítulo, procuramos mostrar que o português não importa, do inglês, apenas palavras prontas; também pode fazer uso produtivo e criativo de inúmeras partículas hoje em circulação na língua doadora, por força da rápida disseminação de palavras e ideias, em decorrência da revolução tecnológica e digital. Não surpreende, portanto, que a grande maioria dos splinters importados esteja relacionada à informática, à computação ou à interação virtual. Nesse particular, as três partículas aqui analisadas evocam o domínio-matriz da informação e focalizam diferentes aspectos dos conteúdos disponibilizados pela rede mundial de computadores: a circulação de vídeos (-tube), a busca pelo conhecimento rápido de algum assunto (-pédia) ou qualquer aspecto mais geral envolvendo as tecnologias de ponta (cyber-).

Numa escala de nativização, -pédia apresenta, mais do qualquer outro splinter do inglês trazido para o português (cf. quadro 4), maior "sentimento de vernaculidade": por conta da existência de 'enciclopédia', nem de longe lembra o correspondente -pedia, sem acento gráfico e pronunciado ['pi:.rie]. Nessa escala, -tube figuraria numa posição intermediária, pois é pronunciado em conformidade com o português, mas mantém a vogal final - $e$, por evocação à fonte, 'You tube', a despeito de termos 'tubo'. No fim da escala, está cyber-, a forma menos nativizada, em função da grafia e da pronúncia originais (a escrita com $<y>$ e a produção do ditongo [aj]).

Embora não sejam propriamente vernaculares, tais partículas acabam se 
ajustando aos esquemas básicos de formação de palavras da língua e podem ser formalizadas como qualquer outra unidade morfológica, pois constituem a parte fixa de construções lexicais. Em todos os casos, tem-se uma herança por subparte, pois o splinter é metonímia formal da palavra-base de que se desprendeu, ou seja, a parte (o fragmento lexical) vale pelo todo (a palavra-fonte).

\title{
A constructional analysis of non native splinters in use in Portuguese of Brazil
}

\begin{abstract}
Based on the constructional morphology, model developed by Booij (2005, 2007, 2010) for the treatment of morphology in construction grammar paradigm (GOLDBERG , 1995), in this article we intend to list the particles of English recently used in morphological structures of Brazilian Portuguese (BP) and describe the formal and semantic features of complex hybrid forms (with a vernacular part and other borrowed). Also, we try to reflect how the new morphological units are integrated in the language, showing that such units conform to the basic schemes of word formation of the BP. Finally, we intend to represent the schemes and subschemas that involved the so-called non native splinters focusing, therefore, the constructions X-tube, cyber-X and X-pedia.
\end{abstract}

Keywords: Morphology. Word formation. Construction grammar. Splinter

\section{Referências}

ADAMS, Valerie. An introduction to modern English word formation. London: Longman, 1973.

ANDRADE, K. E. Proposta de continuum composição-derivação para o português do Brasil. Tese (Doutorado em Letras Vernáculas). Rio de Janeiro: UFRJ, 2013.

ASSUMPÇÃO Jr., A. P. de. Dinâmica léxica portuguesa. Rio de Janeiro: Presença, 1986.

BASÍLIO, M. O princípio da analogia na constituição do léxico: regras são clichês lexicais. Veredas (UFJF), Juiz de Fora, v. 1, p. 9-21, 1997.

BAUER, L. Glossary of morphology. Edinburgh: Edinburgh University Press, 2004. 
BAUER, L. The Borderline between Derivation and Compounding. In: W. Dressler et al. (eds.). Morphology and its Demarcations. Amsterdam / Philadelphia: John Benjamins Publishing Company, 2005, pp. 97-108.

BOOIJ, G. Compounding and Derivation. Evidence for Construction Morphology. In: W. Dressler et al. (eds.). Morphology and its Demarcations. Amsterdam / Philadelphia: John Benjamins Publishing Company, 2005, pp. 109-131.

BOOIJ, G. Construction morphology and the lexicon. In: Montermini, F.; Boyé, G.; Harbout, N. (eds.). Selected proceedings of the 5th Décembrettes Morphology in Toulouse. Somerville MA.: Cascadilla Press, 2007, pp. 34-44.

BOOIJ, G. Construction morphology. Oxford: Oxford University Press, 2010.

CORBIN, D. French (Indo-European: Romance). In: G. Booij, C. Lehmann; J. Mugdan (eds.). Encyclopédie Internationale de Morphologie, Article 121, Berlin, Walter de Gruyer, 2000.

CORREIA, M. Criatividade e Inovação Terminológica - Novos Desafios. Comunicação Inédita apresentada ao Colóquio Internacional A Neologia Científica: balanço e perspectivas. Roma: Organização da União Européia, 2003. GONÇALVES, C. A. Atuais Tendências em Formação de Palavras. São Paulo: Contexto, 2016.

GONÇALVES, C. A. V. Composição e derivação: polos prototípicos de um continuum? Pequeno estudo de casos. Domínios de Lingu@gem, 5, p. 62-89, nov. 2011a.

GONÇALVES, Compostos Neoclássicos: Estrutura e Formação. REVEL - Revista Virtual de Estudos da Linguagem, Porto Alegre, 9 (especial), p. 5-37, 2011 b.

GONÇALVES, C. A. V.; ALMEIDA, M. L. L. Morfologia construcional: principais ideias, aplicação ao português e extensões necessárias. Alfa (ILCSE/ UNESP), v. 58, n. 1, p. 165-193, 2014.

GONÇALVES, C. A.; ALMEIDA, M. L. L. Por uma Cibermofologia: Abordagem Morfossemântica dos Xenoconstituintes em Português. In MOLLICA, M. C.; GONZALEZ, M. (orgs.). Linguística e Ciência da Informação: Diálogos Possíveis. Curitiba: Appris, 2012, pp. 105-127.

GONÇALVES, C. A.; ANDRADE, K. E.; ALMEIDA, M. L. L. Se a macumba é para o bem, então é boacumba: análise morfoprosódica e semântico-cognitiva da substituição sublexical em português. Linguística (Rio de Janeiro), v. 6, p. 64-82, 2010. 
GOLDBERG, A. Constructions: a construction grammar approach to argument structure. Chicago; London: The University of Chicago Press, 1995.

KATAMBA, F. Morphology. New York: Saint Martin Press, 1990.

KEMMER, S. Schemas and Lexical Blends. In: Cuickens, H. et al. (eds). Motivation in Language. Amsterdam/Philadelphia: John Benjamins, 1996, pp. 234-249.

PERINI-SANTOS, P.; MELO, H. Inovações na Morfologia do Português Brasileiro: tendências para a ampliação do léxico por gramaticalização, lexicalização, analogia. Domínios de Lingu@gem. Uberlândia, v. 5, n. 2, 2011, p. 7-29.

PISANI, V. Linguistica generale e indeuropea. Torino: Rosemberg; Sellier, 1967.

SCALISE, S. et alii. Exocentricidade na composição. Gengo Kenkyu 135, p. 4984, 2009.

SOARES da SILVA, A. O mundo dos Sentidos - Polissemia, semântica e cognição. Coimbra: Almeida, 2006.

Submetido: 23/05/2016

Aceite: 05/08/2016 